\title{
Attentional strategies in dichotic listening
}

\author{
JACK BOOKBINDER and ELI OSMAN \\ Brooklyn College of the City University of New York, Brooklyn, New York 11210
}

\begin{abstract}
A person can attend to a message in one ear while seemingly ignoring a simultaneously presented verbal message in the other ear. There is considerable controversy over the extent to which the unattended message is actually processed. This issue was investigated by presenting dichotic messages to which the listeners responded by buttonpressing (not shadowing) to color words occurring in the primary ear message while attempting to detect a target word in either the primary ear or secondary ear message. Less than $40 \%$ of the target words were detected in the secondary ear message, whereas for the primary ear message (and also for either ear in a control experiment), target detection was approximately $80 \%$. Furthermore, there was a significant negative correlation between buttonpressing performance and secondary ear target-detection performance. The results were interpreted as being inconsistent with automatic processing theories of attention.
\end{abstract}

The dichotic listening paradigm, beginning with the experiments of Broadbent (1958) and Cherry (1953), has played a central role in the study of attention during the past two decades. In a dichotic presentation, different auditory messages are simultaneously presented to the subject's right and left ears by means of stereo headphones. In the contrasting dichotic conditions of divided and focused attention (Treisman, 1969), subjects must attend either to the messages in both ears or to only one of the messages. The results of such experiments are quite controversial. Posner and Snyder (1975a), for example, in developing the concept of automatic memory activation, cite certain dichotic listening studies as suggesting that very complicated processing occurs in the unattended ear in focused attention. Shaffer $(1975$, p. 161), on the other hand, points out that the failure of subjects to handle simultaneous auditory messages supports the more pessimistic views on the limits of human attention. Such disparity accentuates the need for a thorough understanding of the attentional strategies available to subjects engaged in various types of dichotic listening tasks.

Much of the ambiguity in dichotic listening research has been due to the possible role that memory might play in specific experimental tasks. If an experimental task has a memory component, it becomes unclear as to whether any attentional effects should be considered as occurring "early" as opposed to "late" in the information

This research was based on a City University of New York doctoral dissertation at Brooklyn College by Jack Bookbinder and was supported by research grants to Eli Osman from the United States Department of Health, Education, and Welfare, Public Health Service (NIH Grant RO1 NS10843) and the PSC-BHE Research Award Program of the City University of New York. The authors wish to thank Shel Feldman and Eric Heinemann for their helpful comments and the time they contributed, and also, Shelly Pazer for her assistance with the preparation of the tapes. Requests for reprints should be sent to Jack Bookbinder, who is now at the Psychology Department, Franklin College, Franklin, Indiana 46131. processing system. Early selection models (Broadbent, 1958, 1971; Treisman, 1960, 1964; Treisman \& Geffen, 1967) allow for analyses of simple physical features simultaneously (e.g., spatial location, voice pitch), while it is postulated that the simultaneous higher order (i.e., semantic context) analysis of all inputs would overload the limited capacity of the perceptual system. For the most part, only the attended message is analyzed beyond the level of simple physical features. Alternatively, late selection models (Deutsch \& Deutsch, 1963; Norman, 1968, 1969; Posner \& Snyder, 1975a, 1975b; Shiffrin, 1975, 1976) attribute all attentional effects to processes that follow full perceptual processing of all incoming stimuli. In the dichotic listening situation, it is assumed that there is an automatic analysis for meaning of all individual verbal items. Attentional mechanisms operating in short-term memory then determine which items (i.e., which ear) are analyzed beyond the level of simple meaning.

In reviewing the existing literature at the time, Egeth (1967, p. 48) commented, "It is surprising how difficult it is to find a study which actually could measure a perceptual effect uncontaminated by a possible influence of memory." An attempt to accomplish this was made by Treisman and Riley (1969). The experiment was performed in response to criticism (Deutsch \& Deutsch, 1967; Lindsay, 1967) of an earlier experiment (Treisman \& Geffen, 1967) that had produced results consistent with the predictions of early selection. Treisman and Riley (1969) presented their subjects with computersynchronized simultaneous dichotic messages consisting of 16 pairs of items at a rate of $1.8 \mathrm{pairs} / \mathrm{sec}$. One pair consisted of a digit on one ear and a letter on the other; both members of the remaining pairs were digits. The primary task was to shadow (repeat word for word) as accurately as possible the digits on one ear. The secondary task was to stop shadowing immediately and to tap with a ruler upon detection of a letter in either ear; target 
letters appeared equally often in each ear. The two messages of each dichotic pair (including the targets) were recorded by the same male voice, except for one condition in which the target letter was recorded by a woman. The subject was told before each trial whether the letter would be spoken by the male voice or the female voice.

The important aspect of this experimental design is that the secondary response (i.e., target detection) is immediate and should not involve memory limitations. In addition, the secondary response is identical regardless of the ear in which the target appears. Nonetheless, when the target letter was in the same (male) voice, Treisman and Riley (1969) found that many more targets were detected in the shadowed ear compared with the nonshadowed ear ("corrected" scores of $76.4 \%$ and $33.4 \%$, respectively). The authors argued that their results confirmed the hypothesis of a perceptual limit in this type of selective listening task. Detection performance was almost perfect in both ears for the different (female) voice targets; this result is consistent with the findings of equal detection performance in the shadowed and nonshadowed ears when the targets are tones and are thus quite distinct from the background message (Lawson, 1966; Zelnicker, Rattock, \& Medem, 1974).

Although the main findings of Treisman and Riley (1969) have been confirmed in several related studies (e.g., Treisman \& Geffen, 1968; Underwood, 1974; Underwood \& Moray, 1971), they have not proved fatal to late selection automatic processing theories (see Shiffrin, 1976; Shiffrin, Pisoni, \& Casteneda-Mendez, 1974). The use of shadowing has been the main source of controversy. Shadowing is a difficult task that does contain a memory component. The average shadowing response lag was found to be three items $(1.2 \mathrm{sec})$, which was about the same as the target-detection latency (Treisman \& Geffen, 1967). It is possible in the Treisman and Riley (1969) experiment that the covert processes (i.e., rehearsal) involved in preparing to shadow the target item might have imparted a substantial advantage to the detection of targets in the shadowed message, even though the detected targets themselves were not shadowed. A further problem in interpreting shadowing experiments arises from the finding (Sullivan, 1976) that detection of word targets in the nonshadowed message increases with the redundancy (approximation to English) of the shadowed message. Underwood and Moray (1971) questioned the reliability of the shadowing technique because of an interaction involving the sex of the shadower and the sex of the target voice; fewer targets were detected when the shadower's own voice was similar to the target voice than when it was different.

There is one aspect inherent in shadowing one message in a dichotic presentation that is of particular importance. In order for a subject to shadow one of the two messages, he must distinguish between the two messages. Assuming that the individual items in both inputs do indeed contact their memory representations
(Posner \& Snyder, 1975a, 1975b), the subject must be sure to shadow the correct one. If memory activation is automatic, there should be opportunity for the subject to shadow items in the "wrong" message. In fact, Treisman and Riley (1969) did report a high percentage (14\%) of intrusions from the wrong ear, and Treisman (1969) has suggested that part of the difficulty in divided attention tasks may be due to the requirement to distinguish between the inputs. It would seem mandatory that the subject develop an active strategy to prevent shadowing of the wrong message. The task of shadowing one of two dichotically presented messages is made more difficult by the assumption of automatic processing of both inputs. The difficulty in shadowing may arise not so much from the act of shadowing itself as from the requirement not to shadow the other message. Salter (1973) required his subjects to shadow one (primary) message and, also, to repeat as much as possible from the other (secondary) message. The slight performance decrement in shadowing the primary message was more than compensated for by the additional words shadowed in the secondary message.

Inasmuch as the requirement to shadow one message seems to demand that the subject ignore the other message, a result other than the one obtained by Treisman and Riley (1969) would be surprising regardless of one's theoretical position. The purpose of the present study was to create a situation in which equal targetdetection performance in both messages of a dichotic presentation would not be at all unlikely, but in which failure to obtain such a result would be clearly inconsistent with the concept of automatic processing. The experimental design was similar to that of Treisman and Riley (1969), with the important exception that the main task did not involve shadowing.

Experiment 1 was the basic experiment and was designed to ensure that any difference in target-detection performance between the two dichotically presented messages could not be attributed to differential memory requirements or the requirement that the two inputs be distinguished (i.e., knowing which message came from which ear). The main task was to immediately press a button upon hearing each of several color words that were interspersed among 20 dichotic word pairs. In addition, the subject was to detect a single predesignated noncolor word on each trial that could appear at either ear. The color words, however, appeared at only one (primary) ear and never at the other (secondary) ear. If both inputs are processed automatically, this arrangement should be of little consequence. The subject's knowledge of which ear receives the color words is actually irrelevant to the response requirements of the task. The subject need only press the button whenever he hears a color word. Thus, the subject should do equally well in detecting the noncolor target words at both primary and secondary ears. If automatic processing does not occur, then a decrement in target-detection performance could be expected for the secondary ear. 
Experiment 2 served as a control condition for Experiment 1. The two were identical in every respect except that the main task in Experiment 2 was to press the button after every third word. This control would not require semantic analysis of the words in either message. The maintaining of dual task conditions in both experiments allows for a fairer comparison of the target-detection rates than would a single-task control condition (see Kantowitz, 1974; Kantowitz \& Knight, 1976). It was expected that target-detection performance would not differ for the two messages of the control. ${ }^{1}$

\section{METHOD}

\section{Subjects}

Thirty-two right-handed Brooklyn College students of both sexes were employed, 16 in Experiment 1 and 16 others in Experiment 2.

\section{Stimuli and Apparatus}

The stimuli and apparatus were identical for both experiments. The word lists were recorded and played to the subjects on a Sony Model TC-270 tape recorder. The recording of the stimulus tapes, as well as of the experiments themselves, took place in a soundproof chamber. The outputs of the tape recorder were low-pass filtered by a Krohn-Hite Model 3202 filter set nominally to pass frequencies below $6,500 \mathrm{~Hz}$. This procedure reduced tape hiss considerably while having little noticeable effect on voice quality. The subjects heard the stimuli over Telephonics TDH-39 headphones. While the subject listened to the word lists, the experimenter monitored the stimulus tape on a second set of headphones. The specific activities of the experimenter were hidden from the subject's view.

The output of the right channel of the tape recorder was rerecorded on the right channel of another tape on a second tape recorder as each subject listened to the stimulus tape. The subject was provided with a normally open pushbutton switch which when depressed caused an electrical tone burst from a Clark-Hess Model 743 function generator to be recorded on the right channel of the second tape recorder. (No tone was heard during the experiment.) A microphone was connected to the left channel of the second tape recorder. Thus, the second tape recorder was simultaneoulsy recording the verbal contents of the right channel of the stimulus tape, buttonpressing responses (tone bursts), and verbal responses of the subject. Upon listening to the "subject tape" at the end of the experimental session, the experimenter could determine when the subject pressed the button or made a verbal response in relation to the words on the stimulus tape. The experimenter and the apparatus were located on one side of the chamber, and the subject sat a few feet away on the other side with pushbutton directly in front of him on the table.

All word lists were recorded by the same female voice at the same rate by keeping in rhythm with the clicks of a memory drum. The clicks were previously recorded on tape at the rate of $1 \mathrm{click} / .6 \mathrm{sec}$, and the speaker listened to them on headphones as she recorded each list. The words used were frequent onesyllable words chosen from Kucrera and Francis (1967). No word appeared in more than one list or more than once within the same list. Special color words (red, blue, green, pink, white black, brown, and gray), however, did appear repeatedly, but a given color word did not appear more than once in the same list. These were the only color words present in any of the lists.

Five monaural lists, each consisting of 20 words, were recorded on the right channel of the tape. Six of the 20 words were color words occurring randomly within the list, with the restrictions that no more than two consecutive words be color words and that a color word could not occur earlier than Position 4 or later than Position 18. Each list began with the introductory words "one, two, three," which were recorded in rhy thm with the 20 words that followed.

Ten dichotic lists were recorded. The right-channel list of each dichotic pair was similar to the monaural lists except that different noncolor words were used. The left-channel list contained 20 noncolor words and was not preceded by the words "one, two, three." After the right-channel list was recorded, the left-channel list was recorded with each pair of the 20 rightleft pairs occurring approximately simultaneously.

There were three main criteria for acceptance of each pair of dichotic lists: (1) Each list had to be recorded in an uninflected monotone; (2) the two lists had to be of approximately equal loudness; and (3) the members of each word pair had to begin approximately simultaneously. It was not essential that word onset asynchrony be reduced to zero. A word pair was accepted as being simultaneous if there was no obvious onset asynchrony that was readily apparent upon listening to the tape. ${ }^{2}$

The 15 lists (5 monaural and 10 dichotic) were recorded consecutively on the same tape with an interval of about $40 \mathrm{sec}$ between the lists. Before each list was played, one noncolor word was designated as a target word. The target word always appeared in the list; in the dichotic lists, the target word could appear in either the right or the left channel. When it appeared in the left channel, it never appeared opposite a color word on the right channel. The target word never occurred earlier than Postition 4 or later than Position 17.

The 15 lists were presented to the subject in consecutive order three times at a comfortable listening level. Each target word was used only once. The targets used during the first (practice) presentation were designated as Set $P$. The other targets comprised Sets 1 and 2. The targets in these two sets for the dichotic lists had a special relationship. For a given list, the target in Set 2 occurred in the same position as the target in Set 1 , but on the opposite channel. In other words, the two targets for a given list were the right- and left-channel members of 1 of the 20 simultaneous pairs in the list. Subjects were not informed of this arrangement. During each of the three presentations of the 10 dichotic lists, five targets appeared in the right channel and five in the left channel. Targets did not appear in the same channel for more than three consecutive lists.

\section{Procedure for Experiment 1}

Inasmuch as the main task was to respond to color words, the right-channel lists containing the color words are referred to as "primary messages." The left-channel lists are referred to as "secondary messages," The terms "primary" and "secondary" are used only as a means of identifying the color and noncolor word lists, respectively.

The 16 subjects were divided evenly in to two groups. The right primary ear group heard the monaural lists and the primary messages of the dichotic lists in the right ear and the secondary messages in the left. The headphones were reversed for the left primary ear group.

The subject was first presented with the five monaural lists in consecutive order. Before each list was played, a card with a target word printed on it was placed on the table in front of the subject; this remained visible during the playing of the list. The experimenter also pronounced the target word out loud. The subject's main task was to press the button in front of him immediately upon hearing each color word. When the subject heard the target word, he was to immediately say the word "now" and stop pressing the button, even though the list would continue. The subject was reminded several times during the experiment that buttonpressing was the main task and it should be as accurate as possible. The eight color words used in the experiment were read to the subject before the first list was presented. The subject was told to immediately release the button after each press so that he would be prepared to press it 
again. It was emphasized that it was just as important not to press at the wrong places (noncolor words) as it was to press to color words. During the break between each list, the next target word was presented and the subject waited for the next list to begin (with the words "one, two, three").

The 10 dichotic lists were then presented to the subject. The subject was told that he would again hear a list of words in the same (primary) ear as in the monaural condition and that he should again press the button each time he heard a color word; a list of 20 different words would be presented simultaneously on the other ear and the target word could appear in either ear. It was specifically mentioned that no color words would ever appear in the other (secondary) ear. If the subject missed the target word, he simply continued the main task until the list ended. The procedure was otherwise identical to that in the monaural condition. The introductory words "one, two, three" were heard only in the primary ear.

The first playing of the 15 lists constituted a practice presentation. Two experimental presentations followed with a break of a few minutes between each presentation. Half of the subjects in each group listened for the targets in Set 1 during the first experimental presentation and for the Set 2 targets during the second experimental presentation. The other subjects listened for the targets in the reverse order. Before the first experimental presentation, the subject was told that he might recognize some of the words in the next set of lists, since the same words were used in the previous (practice) presentation. ${ }^{3}$

Following the playing of the monaural lists, the subject was always informed that the dichotic lists were about to begin. The purpose of presenting the monaural lists prior to the dichotic lists was to give the subject practice in the main task after each break in an easier condition and to re-emphasize the fact that the color words would only appear in the primary ear; the latter was also the reason for having the introductory words presented to the primary ear only. The experimental session was completed in about $1 \mathrm{~h}$.

\section{Procedure for Experiment 2}

The procedure was identical to that of Experiment 1 except for the instructions concerning the main task. The subjects were told to press the button immediately after every third word (pair). Upon detecting a target word in either ear, the subject was to say "now" and stop buttonpressing. (The same target words were used in both experiments.)

Since one message always contained six color words, for consistency, this message is still referred to as the primary message, and the noncolor message as the secondary message. The subjects were again divided into two groups: right primary ear and left primary ear. As in Experiment 1, the monaural lists and the introductory words in the dichotic lists were presented to the primary ear.

The subjects were told before hearing the first practice list that each list contained a number of color words because the same lists were used in a different experiment in which the color words were important. They were told that in this experiment, however, the color words had no special significance. The experimental session was completed in about $1 \mathrm{~h}$.

\section{RESULTS}

\section{Experiment 1}

Upon completion of each experimental session, the experimenter listened to the subject-response tape. The experimenter heard the rerecorded primary message and the tones signifying a buttonpress in the right headphone. The verbal detection response "now" was heard in the left headphone. The approximate latency of each response was determined. If a response occurred before the word following the appropriate word (i.e., color word or target word), the latency was considered to be "immediate." If the response was made during the presentation of the following word, the latency was " $1 / 2 / 2$ word"; if it was made during the interval between the following word and the next word, the latency was " 1 word," and so on. The results reported are from the two experimental presentations and not from the practice presentation.

For the main task, the measure of performance used is percent correct buttonpresses. For each list, the number of color words that occurred prior to the target word was determined. This number represents the maximum number of correct responses for the list. For the dichotic lists, the maximum number of correct responses for all trials was 58; for the monaural trials, it was 27. Inasmuch as the results for the two experimental presentations were quite similar (i.e., no order effect), the corresponding data were combined for each subject. The measure of performance is defined as:

\section{percent correct buttonpresses}

$$
=\frac{\text { total number of correct buttonpresses }}{\text { maximum number of correct buttonpresses }}
$$

Only responses made to color words occurring prior to the target word were considered. (If a subject missed the target word, he kept responding to color words that followed the target word.) Thus, the percentages for all subjects are based on the same maximum. There were only a few scattered instances of false buttonpresses in the entire experiment, and these were treated as if they had not occurred.

The mean buttonpressing performance scores for the dichotic and monaural conditions were $81.6 \%$ and $90.3 \%$, respectively (see Table 1 ). The latency for most responses was "immediate." This means that most responses were made within $.6 \mathrm{sec}$ from the onset of the color word. With few exceptions, all responses were initiated with latencies of $1 \frac{112}{2}$ words or less, within approximately $1.2 \mathrm{sec}$ from the onset of the color word. This compares with the mean shadowing latency reported by Treisman and Geffen (1967) of about three words, which was equivalent to $1.2 \mathrm{sec}$ in that experiment (Treisman, 1967).

The number of target words detected by each subject in the primary and secondary messages was determined for each experimental presentation. The results were again quite similar for the two presentations, so the data were combined. Each subject had the opportunity to detect 10 targets in the monaural lists and 10 targets each in the primary and secondary messages of the dichotic lists. Except for one subject who detected only 
Table 1

Mean Performance Scores for the Main Task and Target Detection (Experiment 1)

\begin{tabular}{lrccccc}
\hline & & \multicolumn{2}{c}{ Number of Targets Detected } & & \multicolumn{2}{c}{ Percent Correct Buttonpresses } \\
\cline { 6 - 7 } \cline { 6 - 7 } & $\mathrm{n}$ & Primary & Secondary & & Dichotic & Monaural \\
\hline Right Primary Ear & 8 & 8.50 & 3.75 & 80.8 & 86.8 \\
Left Primary Ear & 8 & 8.12 & 3.75 & 82.3 & 94.0 \\
All Subjects & 16 & 8.31 & 3.75 & 81.6 & 90.3 \\
\hline
\end{tabular}

eight targets, detection performance in the monaural condition was perfect. The results for the dichotic condition are shown in Table 1. The difference between the mean number of targets detected in the primary and secondary messages (8.31 and 3.75 , respectively) was highly significant [correlated $t(15)=5.97, \mathrm{p}<.001$ ] Of the 16 subjects, 13 detected more targets in the primary message than in the secondary message, with the difference ranging up to the maximum possible of 10 , that is, 10 targets detected in the primary message and none in the secondary message. The maximum dif ference in favor of the secondary message was 1 .

The target-detection results show that, with the requirement to respond to color words in the primary message, there is severe disruption of the detection of target words in the secondary message. As discussed earlier, this result is quite important, inasmuch as the main task did not require the subject to distinguish between the two ears (inputs) in any way. There was, however, a wide range of performance in the detection of secondary message targets, as three subjects missed all of the secondary message targets, while one subject detected eight. Although it was carefully explained to each subject that it was important that buttonpressing be as accurate as possible, performance in the main task ranged from $70.7 \%$ to $98.3 \%$. A tradeoff between the two tasks exists: Those subjects who did better in the target-detection task did so at the expense of buttonpressing performance. All subjects who achieved performance above the mean $(81.6 \%)$ in the main task detected fewer than the mean number (3.75) of secondary message targets detected. All subjects who detected more than the mean number of secondary message targets detected had buttonpressing scores below the mean. (Only two subjects scored below the mean in both tasks.) The strength of the inverse relationship between the two performance measures is quantified by the correlation coefficient (Pearson r), which was found to be $-.588[t(14)=2.72, p<.02]$. In contrast, there was no obvious relationship $(r=-.079)$ between performance in the main task and the detection of primary message targets.

The relationship between performance in the two tasks is summarized in Table 2. Note that monaural buttonpressing performance was high even for those subjects whose dichotic buttonpressing performance was inferior. Of most interest is the fact that while the mean number of secondary message targets for all subjects was 3.75 , the mean number of targets detected by those subjects with superior main task performance was only 1.33. Thus, only $13 \%$ of the secondary message targets were detected by those subjects who seemed to best follow the task instructions. As can be seen in Table 2, buttonpressing performance for these subjects did not decline in the dichotic condition relative to the monaural condition. (The relatively fast presentation rate most likely accounts for the fact that monaural performance was not perfect; it certainly indicates that the main task was not trivial.)

\section{Experiment 2}

For the control data, the two experimental presentations were also quite similar and were thus combined for each subject. Most subjects responded perfectly in the main task, responding precisely after every third word. Other subjects made an occasional error on one or two lists such as responding after Words $3,6,10,12$, and 15 instead of Words $3,6,9,12$, and 15 . Some subjects had a tendency to make slightly delayed responses, so that the tone on the subject tape partly overlapped the word following the third word. The generally excellent performance in this task was expected inasmuch as the responses occurred at well defined equal time intervals (see Hamilton \& Hockey, 1974).

In the monaural condition, target-detection performance was perfect except for one subject who missed

Table 2

Performance Summary for Experiment 1

\begin{tabular}{cccccccc}
\hline & & \multicolumn{2}{c}{ Number of Targets Detected } & & \multicolumn{2}{c}{ Percent Correct Buttonpresses } \\
Performance* & $\mathrm{n}$ & Primary & Secondary & & Dichotic & Monaural \\
\hline Superior & 6 & 8.50 & 1.33 & 90.2 & 90.1 \\
Inferior & 10 & 8.20 & 5.20 & & 76.4 & 90.4 \\
\hline
\end{tabular}

Note-For all 16 subjects, the mean value for performance in the dichotic condition was $81.6 \%$ correct buttonpresses. The performance of six subjects was at a level above the mean. The remaining 10 subjects performed at a level below the mean. The mean value divides "inferior" and "superior" performance.

*Mean values for subjects with superior/inferior performance in the main task. 
1 of the 10 targets. The target-detection results for the dichotic condition are indicated in Table 3. The difference between the mean number of targets detected in the primary and secondary messages (7.94 and 7.62, respectively) was clearly nonsignificant [correlated $t(15)=.47, p>.60]$. Half of the subjects detected more targets in the secondary message, with the largest obtained difference being five targets; this contrasts sharply with the results of Experiment 1, in which 4.56 more targets, on the average, were detected in the primaty message. ${ }^{4}$

The results can perhaps be better appreciated by looking at the detectability of individual target words. ${ }^{5}$ The data in Table 4 indicate the number of subjects (out of 16) who detected each target word in each of the two experiments. For example, 14 subjects detected the primary message target of List 1 in Experiment 1 and 15 subjects detected it in Experiment 2. The secondary message target for List 1 was detected by only 6 subjects in Experiment 1 as compared with 11 in Experiment 2; the same target word was detected by 5 fewer subjects in Experiment 1. For every list, the secondary message target was detected by fewer subjects in Experiment 1 than in Experiment 2; the mean difference was -6.2 subjects. For the primary messages, some targets were detected by more subjects in Experiment 1 and others were detected by more subjects in Experiment 2; the maximum difference was only four subjects (List 4).

The results of Experiment 2 are useful for revealing the magnitude of the effects observed in Experiment 1. Approximately $80 \%$ of the targets were detected in the primary message in each of the two experiments, as well as in the secondary message in Experiment 2. Performance for the secondary message in Experiment 1 stood apart, however, as only $37.5 \%$ of the targets were detected; even those subjects with inferior buttonpressing performance in the main task detected only $52 \%$ of the targets (Table 2). Thus, strong attentional effects were found, despite the fact that the shadowing technique was not used and an overt response was not required for every item in the primary message.

\section{DISCUSSION}

The results of this study are compatible with capacitysharing models of attention that do not assume automatic processing (e.g., Kahneman, 1973; Norman \& Bobrow,

Table 3

Mean Number of Targets Detected (Experiment 2)

\begin{tabular}{lrcc}
\hline & & \multicolumn{2}{c}{$\begin{array}{c}\text { Number of Targets } \\
\text { Detected }\end{array}$} \\
\cline { 2 - 4 } & $\mathrm{n}$ & Primary & Secondary \\
\hline Right Primary Ear & 8 & 8.62 & 7.50 \\
Left Primary Ear & 8 & 7.25 & 7.75 \\
All Subjects & 16 & 7.94 & 7.62 \\
\hline
\end{tabular}

Table 4

Number of Subjects Who Detected Each Target Word

\begin{tabular}{cccccc} 
& \multicolumn{2}{c}{ Primary Message } & & \multicolumn{2}{c}{ Secondary Message } \\
\cline { 2 - 3 } \cline { 5 - 6 } List & \multicolumn{2}{c}{ Experiment } & & \multicolumn{2}{c}{ Experiment } \\
1 & 14 & 15 & 6 & 11 \\
2 & 16 & 14 & 6 & 11 \\
3 & 15 & 14 & 7 & 13 \\
4 & 12 & 8 & 8 & 15 \\
5 & 15 & 15 & 3 & 10 \\
6 & 13 & 15 & 7 & 13 \\
7 & 7 & 10 & 7 & 13 \\
8 & 13 & 12 & 2 & 10 \\
9 & 15 & 13 & 7 & 13 \\
10 & 13 & 11 & 7 & 13 \\
Mean & 13.3 & 12.7 & 6.0 & 12.2 \\
Percent & 83.1 & 79.4 & 37.5 & 76.2 \\
\hline
\end{tabular}

1975). In performing the relatively easy main task of Experiment 2, the subjects were able to divide their attention evenly between the two ears and detect a large proportion of the target words in either message. In Experiment 1, however, the subjects found it necessary to focus their attention on the primary ear in order to respond to color words present in that ear. This uneven distribution of attention lowered considerably the probability of detecting a target in the secondary ear. Some subjects raised this probability by apparently deploying additional attention (capacity) to the secondary ear; the cost of this strategy was a worsening of performance in the main task. Surprisingly, perhaps, there was little, if any, loss in the detectability of target words in the primary message.

The terminology introduced by Norman and Bobrow (1975) is quite useful in describing the picture that emerges from the present results. Since it appears that main task performance in Experiment 1 was dependent on the amount of processing capacity (resource) allocated to the primary ear, this task is "resource limited." Investment of a relatively small amount of capacity in the secondary ear improved target-detection performance in that ear; this task is also resource limited. The corresponding small decrease in the capacity available to the primary ear did not result in any noticeable drop in the high detection rate of primary message targets; the task is "data limited." The target-detection results thus illustrate the point made by Norman and Bobrow (1975) that whether a given task may appear to be resource or data limited depends on the specific portion of the "performance-resource function" under consideration.

Implicit in this discussion is the assumption of a central source of limited capacity that can be freely allocated to different mental activities (Kahneman, 1973). The subjects in Experiment 1 showed flexibility in attentional strategy by regulating the disparity between the capacity allotment to each ear; this is reflected in the 
negative correlation between main task performance and secondary message target detection. Note that subjects were able to effect a relatively large increase in secondary message target detection at the cost of a relatively small decrease in main task performance (see Table 2). Such a strategy is appropriate for subjects more concerned with optimal overall performance (Kahneman, 1970) than with optimal performance in the main task.

In the experiment of Treisman and Riley (1969), subjects shadowed the digits on one ear but stopped shadowing and tapped when detecting a letter on either ear. When the target letters and the digits were in the same voice, many targets were missed in the nonshadowed ear. According to the automatic processing model of Shiffrin (1976), targets are located by means of a "controlled search" of short-term memory, and shadowing forces the search to begin with the material being shadowed. By the time the search switches to the other ear, the target there may have been already replaced by a new item, or new material on the shadowed ear may require the search to return there. Thus, many targets will be missed on the nonshadowed ear, despite automatic processing of both inputs.

The question at hand is whether Shiffrin's (1976) approach can adequately handle the results obtained in the present experiments. In Experiment 1, performance in the detection of a specific target word was poor in the secondary ear. Following Shiffrin's (1976) reasoning, this result might be explained by assuming that the main task (i.e., pressing to color words in the primary ear) caused the controlled search for the target word to begin in the primary ear. Such an explanation is not very convincing for several reasons. Of particular importance are the specific differences between the shadowing task and the main task in Experiment 1. Shadowing is made difficult by several factors: (1) The task requires the subject to distinguish between the inputs, thus forcing the subject to attend to one ear; (2) the subject must give continuous responses to each item presented; and (3) each response is dependent on the specific verbal item presented, with the response usually made after several other items have been presented. The main task in Experiment 1 did not force the subject to distinguish between the inputs and did not require the subject to respond to each item presented. Furthermore, the simple buttonpressing response was identical regardless of the specific identities of the color words. Buttonpressing responses were immediate or only slightly delayed.

Assuming that the information in both messages was automatically deposited in short-term memory, it is not at all clear why the color words could not be responded to without a controlled search beginning with the material in the primary ear. There were only two inputs, easily separable by location, clearly perceivable, and presented at a fast but not excessive rate. The targets themselves were single-syllable frequent words. Such phonemic targets are easier to detect than category targets (Sullivan,
1976; Treisman \& Geffen, 1967). For Shiffrin (1976), it is convenient to have all of the incoming information present in short-term memory in explaining why subjects might respond (incorrectly) to material in the unattended ear in a focused attention task. The assumption of automatic processing, however, makes the explanations of certain divided attention effects (e.g., Experiment 1) somewhat strained.

Note here that theorists who do not assume automatic processing attack the problem from the opposite perspective. Meaning, expectations, and context all play important roles in the models of Broadbent (1971), Kahneman (1973), and Treisman (1960, 1964; Treisman \& Geffen, 1967). They are necessary to explain why some items in the unattended ear or secondary inputs are responded to in the absence of automatic processing. The problem for Shiffrin (1976) is reversed; rather than explaining why some targets are detected, he is faced with the task of explaining why most are not.

In Experiment 1, target-detection performance in the secondary ear was extremely poor for those subjects with superior buttonpressing performance. Adopting Shiffrin's (1976) terminology and assuming automatic processing, good performance in the main task required that a controlled search for the target word (secondary task) begin in the primary ear. As a result of the fast presentation rate and decisions necessary in the main task, search time for secondary ear targets could be expected to be limited and insufficient. When some subjects increased this search time, more secondary ear targets were detected as fewer color words in the primary ear were responded to. If this is indeed the case, it seems that fewer primary ear targets should have been detected as search time in the secondary ear increased. However, detection performance in the primary ear was independent of detection performance in the secondary ear and buttonpressing performance.

Shaffer and Hardwick (1969) suggested that the commitment to translate a signal into a response might limit or interfere with the recognition of items on the unattended ear. Moray (1975) and Sorkin (Pohlman \& Sorkin, 1976; Sorkin \& Pohlman, 1973; Sorkin, Pohlman, \& Woods, 1976) have incorporated the concept of an "interrupt" process in their models of attention; the detection of a target on one channel interrupts processing on another channel. In terms of Shiffrin's (1976) model, one might speculate that the detection of a color word interrupts the controlled search for items on the secondary ear, even though secondary ear targets never appeared simultaneously with a color word. Since the subject was making repeated responses at a rapid rate, the controlled search for the target word would have little opportunity to switch to the secondary ear. Shiff rin (1976) notes that negative decisions concerning the presence of a target may be faster than positive decisions, due to possible rechecking in the case of positive decisions. In Experiment 2, in which no positive 
decisions occurred until the target appeared, the subject might have been able to conduct a controlled, backand-forth search in both inputs so that detection performance was good in both ears. An efficient controlled search would be impeded in Experiment 1 because of the repeated, longer, positive decisions required in the main color word-detection task.

Acceptance of an interrupt hypothesis as the explanation for the results of Experiment 1 suggests that the detection of a given secondary ear target should be at least partly dependent on its proximity to color words on the primary ear. Such was not the case, however. Detection performance was poor for all targets in the secondary message and did not improve for targets that were relatively distant from color words. Furthermore, examination of individual subject-response patterns did not reveal any relationship between target detection and misses of adjacent color words; that is, there was no tendency for secondary message targets to be detected when nearby color words were missed. One special case is the target word in List 9, which occurred in Position 4 before any color words appeared. Even so, only 7 subjects detected this secondary message target in Experiment 1 as compared with 13 in Experiment 2 (Table 4). This result is particularly impressive, for it demonstrates that overt responses are not a necessity for attention to be "locked" into a selected message. Thus, strong attentional effects were obtained despite the fact that the popular shadowing technique was not used as a method of directing the subject's attention to a given ear.

Not only do the present results argue against automatic processing, but there is now considerable doubt about conclusions based upon the results of earlier experiments that seemed to favor automatic processing. Lewis (1970) required his subjects to shadow a list of words in one ear while a different list of words was simultaneously presented to the unattended ear. He found that shadowing latencies increased when a synonym of the shadowed word was presented simultaneously on the unattended ear. This suggested to Lewis (1970) that the unattended message did enjoy the benefit of full perceptual (semantic) analysis. Treisman, Squire, and Green (1974) questioned this conclusion. They replicated the synonym effect but found that it occurred only for synonyms occurring early in the list. Furthermore, the data indicated that the early increased reaction time was due to a few very long latencies rather than a small increase on every trial. Treisman et al. (1974) suggested, therefore, that it might take time for capacity to become fully loaded by the attended (shadowed) message and for efficient focusing to take place. Support for this hypothesis comes from a study by Ambler, Fisicaro, and Proctor (1976). Using pupil dilation as a measure of the momentary mental effort (Kahneman, 1973) invested in a task, they found that pupil size decreased over time as shadowing continued, in agreement with the proposal that it takes time for attention to become focused on the relevant message.

of considerable interest are those dichotic listening studies that have utilized the galvanic skin response (GSR) as a means of indirectly determining the extent to which the unattended message is actually processed. Corteen and Dunn (1974), Corteen and Wood (1972), Moray (1970), and von Wright, Anderson, and Stenman (1975) have reported GSR changes in response to critical items on the nonshadowed ear, despite the lack of awareness of these items claimed by the subjects. Recently, however, these findings have come under attack. Bowers and Brenneman (Note 1) attempted an exact replication of the Corteen and Wood (1972) experiment. Not only did they fail to replicate the original findings, but the authors report that Corteen (cited in Bowers \& Brenneman, Note 1) indicated to them in a personal communication that he had been unable to replicate the effect after the first two studies. Wardlaw and Kroll (1976) also failed in an attempt to replicate the results of Corteen and Wood (1972). These failures to replicate the results of GSR dichotic listening experiments are quite important because of the frequency with which such experiments are cited as evidence for automatic processing. As Wardlaw and Kroll (1976, p. 360) note, "It would seem that the semantic processing of words presented in the nonattended message, while subjects shadow the attended message, is more difficult to obtain than one would believe from a cursory reading of the literature."

In summary, it is suggested that the current trend toward acceptance of the automatic processing view of perception and attention is unwarranted. The results reported in the present paper are consistent with a view of attention that assumes the existence of a limited supply of central processing capacity that can be divided among concurrent activities or tasks. Limitations in task performance will appear when the demands placed on this limited supply exceed the amount of capacity available. When such limitations do not arise (i.e., simultaneous processing), it does not necessarily mean that the particular processes under consideration occur automatically and independently of the available processing capacity. Rather, it is more likely that the available processing capacity (or resource) was sufficient to meet the needs of the tasks involved. A proper understanding of the performance levels reached in a dual task or divided attention experiment is very much dependent upon a thorough appreciation of the nature of the individual tasks and the optional strategies available to the subjects. These strategies are best described as allocation strategies for the continuous flow of processing capacity.

\section{REFERENCE NOTE}

1. Bowers, K. S., \& Brenneman, H. A. Unattended information and hypnotic susceptibility. Paper presented at the convention of the Society for Clinical and Experimental Hypnosis, Montreal, 1974. 


\section{REFERENCES}

Ambler, B., Fisicaro, S. A., \& Proctor, R. W. Temporal characteristics of primary-secondary message interference in a dichotic listening task. Memory \& Cognition, 1976, 4, 709-716.

BOoKBINDER, J. Attentional strategies and processing capacity in dichotic listening. Unpublished doctoral dissertation, City University of New York, 1978.

Broadbent, D. E. Perception and communication. London: Pergamon Press, 1958.

Broadbent, D. E. Decision and stress. New York: Academic Press, 1971.

CherRY, E. C. Some experiments on the recognition of speech, with one and two ears. Journal of the Acoustical Society of America, 1953, 25, 975-979.

Corteen, R. S., \& DunN, D. Shock-associated words in a nonattended message: A test for momentary awareness. Journal of Experimental Psychology, 1974, 102, 1143-1144.

Corteen, R. S., \& Wood, B. Autonomic responses to shockassociated words in an unattended channel. Journal of Experimental Psychology, 1972, 94, 308-313.

Deutsch, J. A., \& Deutsch, D. Attention: Some theoretical considerations. Psychological Review, 1963, 70, 80-90.

Deutsch, J. A., \& Deutsch, D. Comments on "Selective attention: Perception or response?" Quarterly Journal of Experimental Psychology, 1967, 19, 362-363.

Egeth, H. E. Selective attention. Psychological Bulletin, 1967, 67, 41-57.

Hamilton, P., \& Hockey, R. Active selection of items to be remembered: The role of timing. Cognitive Psychology, 1974, 6, 61-83.

Kahneman, D. Remarks on attention control. Acta Psychologica, 1970, 33, 118-131.

Kahneman, D. Attention and effort. Englewood Cliffs, N.J: Prentice-Hall, 1973.

Kahneman, D. Effort, recognition and recall in auditory attention. In P. M. A. Rabbitt \& S. Dornic (Eds.), Attention and performance $V$. New York: Academic Press, 1975.

Kantowitz, B. H. Double stimulation. In B. H. Kantowitz (Ed.), Human information processing: Tutorials in performance and cognition. Hillsdale, N.J: Erlbaum, 1974.

Kantowitz, B. H., \& KNIGHT, J. L., JR. On experimenterlimited processes. Psychological Review, 1976, 83, 502-507.

KuČ́ra, H., \& Francrs, W. N. Computational analysis of present-day American English. Providence, R.I: Brown University Press, 1967.

Lawson, E. A. Decisions concerning the rejected channel. Quarterly Journal of Experimental Psychology, 1966, 18, 260-265.

LEWIS, J. L. Semantic processing of unattended messages using dichotic listening. Journal of Experimental Psychology, 1970, 85, 225-228.

Lindsay, P. H. Comments on "Selective attention: Perception or response?" Quarterly Journal of Experimental Psychology, $1967,19,363-364$

Massaro, D. W. Perceptual processing in dichotic listening. Journal of Experimental Psychology: Human Learning and Memory, 1976, 2, 331-339.

MEwhort, D. J. K. Retrieval tags and order of report in dichotic listening. Canadian Journal of Psychology, 1973, 27, 119-126.

Moray, N. Attention: Selective processes in vision and hearing. New York: Academic Press, 1970.

Moray, N. A data base for theories of selective listening. In P. M. A. Rabbitt \& S. Dornic (Eds.), Attention and performance $V$. New York: Academic Press, 1975.

Norman, D. A. Towards a theory of memory and attention. Psychological Review, 1968, 75, 522-536.

Norman, D. A. Memory while shadowing. Quarterly Journal of Experimental Psychology, 1969, 21, 85-93.

Norman, D. A., \& Bobrow, D. G. On data-limited and resourcelimited processes. Cognitive Psychology, 1975, 7, 44-64.

Pohlman, L. D., \& Sorkin, R. D. Simultaneous three-channel signal detection: Performance and criterion as a function of order of report. Perception \& Psychophysics, 1976, 20, 179-186.

Posner, M. I., \& Snyder, C. R. R. Attention and cognitive control. In R. L. Solso (Ed.), Information processing and cog. nition: The Loyola symposium. Hillsdale, N.J: Erlbaum, 1975. (a)

Posner, M. I., \& SNyder, C. R. R. Facilitation and inhibition in the processing of signals. In P. M. A. Rabbitt \& S. Dornic (Eds.), Attention and performance $V$. New York: Academic Press, 1975. (b)

SAlte R, D. Shadowing at one and at two ears. Quarterly Journal of Experimental Psychology, 1973, 25, 549-556.

Shaffer, L. H. Multiple attention in continuous verbal tasks. In P. M. A. Rabbitt \& S. Dornic (Eds.), Attention and performance $V$. New York: Academic Press, 1975.

Shaffer, L. H., \& Hardwick, J. Monitoring simultaneous auditory messages. Perception \& Psychophysics, 1969, 6, 401-404.

Shiffrin, R. M. The locus and role of attention in memory systems. In P. M. A. Rabbit \& S. Dornic (Eds.), Attention and performance $V$. New York: Academic Press, 1975.

Shiffrin, R. M. Capacity limitations in information processing, attention, and memory. In W. K. Estes (Ed.), Handbook of learning and cognitive processes (Vol. 4). Hillsdale, N.J: Erlbaum, 1976

Shiffrin, R. M., Pisoni, D. B., \& Casteneda-Mendez, K Is attention shared between the ears? Cognitive Psychology, $1974,6,190-215$

Sorkin, R. D., \& Pohlman, L. D. Some models of observer behavior in two-channel auditory signal detection. Perception \& Psychophysics, 1973, 14, 101-109.

Sorkin, R. D., Pohlman, L. D., \& Woods, D. D. Decision interaction between auditory channels. Perception \& Psychophysics, 1976, 19, 290-295.

Sullivan, L. Selective attention and secondary analysis: A reconsideration of Broadbent's filter model of selective attention. Quarterly Journal of Experimental Psychology, 1976, 28, 167-178.

Treisman, A. M. Contextual cues in selective listening. Quarterly Journal of Experimental Psychology, 1960, 12, 242-248.

Treisman, A. M. Selective attention in man. British Medical Bulletin, 1964, 20, 12-16.

Treisman, A. M. Reply to "Comments on 'Selective attention: Perception or response?" "Quarterly Journal of Experimental Psychology, 1967, 19, 364-367.

Treisman, A. M. Strategies and models of selective attention: Psychological Review, 1969, 76, 282-299.

Treisman, A. M., \& Gefren, G. Selective attention: Perception or response? Quarterly Journal of Experimental Psychology, $1967,19,1-17$

Treisman, A. M., \& Gefren, G. Selective attention and cerebral dominance in perceiving and responding to speech messages. Quarterly Journal of Experimental Psychology, 1968, 20, 139-150.

Treisman, A. M., \& Riley, J. G. A. Is selective attention selective perception or selective response? A further test. Journal of Experimental Psychology, 1969, 79, 27-34.

Treisman, A. M., Squire, R., \& Green, J. Semantic processing in dichotic listening? A replication. Memory \& Cognition, 1974, 2, 641-646

UNDERwood, G. Moray vs. the rest: The effects of extended shadowing practice. Quarterly Journal of Experimental Psychology, 1974, 26, 368-372.

UNDERWOOD, G., \& Moray, N. Shadowing and monitoring for selective attention. Quarterly Journal of Experimental Psychology, 1971, 23, 284-295.

von Wright, J. M., Anderson, K., \& Stenman, U. Generalization of conditioned GSRs in dichotic listening. In P. M. A. Rabbitt \& S. Dornic (Eds.), Attention and performance $V$. New York: Academic Press, 1975.

Wardlaw, K. A., \& Kroll, N. A. E. Autonomic responses to 
shock-associated words in a nonattended message: A failure to replicate. Journal of Experimental Psychology: Human Perception and Performance, 1976, 2, 357-360.

Zelnicker, T., Rattock, J., \& Medem, A. Selective listening for tones appearing on a relevant and on an irrelevant input channel. Perception \& Psychophysics, 1974, 16, 50-52.

\section{NOTES}

1. Another possible control condition would be to have the color words present in both the right- and leftear messages, but to leave the tasks of Experiment 1 otherwise unchanged. Targetdetection performance would be expected to be equal for both messages (with proper balancing in the event of a right-ear advantage). This would necessitate that the subjects in the two experiments listen to different tapes. Experiment 2 was specifically designed to allow comparisons to be made in a situation in which all subjects in the study listened to the identical stimulus tapes.

2. The asynchrony was measured, however, by feeding the two channels of the tape recorder into a dual storage oscillo. scope and making a direct visual comparison between the onset times of both members of each word pair. The complete word lists with the approximate asynchronies of each word pair are presented in Bookbinder (1978). These asynchrony measurements indicated that there was no tendency for one of the words in each pair (right or left channel) to lead the other.

3. The subjects' comments in this study suggested that there was very little retention of individual words as a result of repeated presentations of the lists, and this was clearly confirmed by the results of an independently run control study. Each subject listened to two complete presentations of the dichotic lists. The task was simply to press the button upon detection of a predesignated target word; on half of the trials, the subject was told in advance of the playing of the list the ear in which the target word would appear. A surprise confidence-rating recognition test followed, in which subjects also indicated the ear in which they thought each test word had appeared. Recognition performance (ignoring ear location responses) was poor, as hit and false alarm rates did not significantly differ. Statistical analysis of the results also indicated little, if any, retention of spatial information. The latter result is consistent with recent studies (Kahneman, 1975; Massaro, 1976; Mewhort, 1973) that have shown that retention of spatial information for dichotic lists is poor, even when the recognition test is administered immediately after a short list is heard.

4. In Experiment 1, considerably more targets were detected in the primary message, regardless of the ear on which each was presented. If one ignores which message each target occurred in but considers which ear it occurred in, the mean numbers of targets detected in Experiment 2 in the right and left ears were 8.19 and 7.38 , respectively (see Table 3 ). This small right-ear advantage was not statistically significant [correlated $t(15)=$ $1.28, \mathrm{p}>.20]$.

5. There was no obvious relationship between the detectability of individual target words and word onset asynchrony.

(Revision accepted for publication May 15, 1979.) 